\title{
LSPS/Optogenetics to Improve Synaptic Connectivity Mapping: Unmasking the Role of Basket Cell-Mediated Feedforward Inhibition
}

\author{
Julia Brill,, Joanna Mattis, ${ }^{2,3}$ Karl Deisseroth,, ${ }^{2,4,5}$ and ${ }^{1}$ John R. Huguenard ${ }^{1}$
}

\section{DOI:http://dx.doi.org/10.1523/ENEURO.0142-15.2016}

\begin{abstract}
${ }^{1}$ Department of Neurology and Neurological Science, Stanford University, Stanford, California 94305, ${ }^{2}$ Department of Bioengineering, Stanford University, Stanford, California 94305, ${ }^{3}$ Neuroscience Program, Stanford University, Stanford, California 94305, ${ }^{4}$ CNC Program, Stanford University, Stanford, California 94305, and ${ }^{5}$ Department of Psychiatry and Behavioral Sciences, Stanford University, Stanford, California 94305
\end{abstract}

\begin{abstract}
Neocortical pyramidal cells (PYRs) receive synaptic inputs from many types of GABAergic interneurons. Connections between parvalbumin (PV)-positive, fast-spiking interneurons ("PV cells") and PYRs are characterized by perisomatic synapses and high-amplitude, short-latency IPSCs. Here, we present novel methods to study the functional influence of PV cells on layer 5 PYRs using optogenetics combined with laser-scanning photostimulation (LSPS). First, we examined the strength and spatial distribution of PV-to-PYR inputs. To that end, the fast channelrhodopsin variant AAV5-EF1 $\alpha$-DIO-hChR2(E123T)-eYFP (ChETA) was expressed in PV cells in somatosensory cortex of mice using an adeno-associated virus-based viral construct. Focal blue illumination (100-150 $\mu \mathrm{m}$ half-width) was directed through the microscope objective to excite PV cells along a spatial grid covering layers 2-6, while IPSCs were recorded in layer 5 PYRs. The resulting optogenetic input maps showed evoked PV cell inputs originating from an $\sim 500-\mu \mathrm{m}$-diameter area surrounding the recorded PYR. Evoked IPSCs had the short-latency/ high-amplitude characteristic of PV cell inputs. Second, we investigated how PV cell activity modulates PYR output in response to synaptic excitation. We expressed halorhodopsin (eNpHR3.0) in PV cells using the same strategy as for ChETA. Yellow illumination hyperpolarized eNpHR3.0-expressing PV cells, effectively preventing action potential generation and thus decreasing the inhibition of downstream targets. Synaptic input maps onto layer 5 PYRs were acquired using standard glutamate-photolysis LSPS either with or without full-field yellow illumination to silence PV cells. The resulting IPSC input maps selectively lacked short-latency perisomatic inputs, while EPSC input maps showed increased connectivity, particularly from upper layers. This indicates that glutamate uncaging LSPS-based excitatory synaptic maps will consistently underestimate connectivity.
\end{abstract}

Key words: connectivity mapping; laser-scanning photostimulation; neocortex; optogenetics; parvalbumin; pyramidal cells

\section{Significance Statement}

Neural computations depend on the interplay of synaptic and intrinsic neuronal properties within complex networks of interconnected neurons. It is of particular interest how individual GABAergic interneuron types modulate network dynamics. Here, we outline novel methods to study connectivity between PV cells, a prominent type of neocortical GABAergic interneuron, and pyramidal cells (PYRs), the main principal neurons of the neocortex. Using optogenetic methods and laser-scanning photostimulation, we map the spatial extent and synaptic characteristics of parvalbumin (PV)-to-PYR connections, and demonstrate a substantial role of PV cells in spatially specific feedforward inhibition of PYRs. These methods can be used to better quantify the role of interneuron types in modulating input to and output of PYRs. 


\section{Introduction}

Neocortical interneurons comprise a variety of different types that can be distinguished based on their morphology, marker protein expression patterns, and intrinsic electrophysiological properties (Yuste, 2005; Rudy et al., 2011; Kepecs and Fishell, 2014). They also differ with respect to their role and position within neuronal circuits. For example, parvalbumin (PV)-positive, fast-spiking interneurons ("PV cells") have relatively short arborizations and synapse onto the cell bodies, proximal dendrites, or axon initial segments of pyramidal cells (PYRs; MarinPadilla, 1970; Somogyi, 1977). As a result, they provide localized, strong, and fast inhibition; and can veto action potential generation in PYRs (Freund and Katona, 2007), and PYRs and PV cells can dynamically influence each other (Lourenço et al., 2014). Focal activation via glutamate uncaging rapidly recruits powerful perisomatic inhibition (Brill and Huguenard, 2009). At the other extreme, Martinotti cells tend to avoid perisomatic contacts but instead target distal dendrites of PYRs and provide mainly shunting inhibition (Silberberg and Markram, 2007; Murayama et al., 2009). To understand the dynamics of neuronal circuits, it is necessary to tease out the roles of the individual interneuron subtypes. This has been done mostly using anatomical techniques to identify neurons based on morphology and marker protein expression, which allows drawing certain conclusions regarding the connectivity pattern based on their morphology and overlap with arborizations of other cells. Another technique is paired recordings, which reveal the strength and kinetics of the synaptic connections between identified cell types, as well as their connection probability (Thomson and Bannister, 1998; Sotelo, 2003; Bannister and Thomson, 2007; Bock et al., 2011; Packer et al., 2013; van Pelt and van Ooyen, 2013; Qi et al., 2015). These approaches provide valuable insights into cortical circuits that could not easily gained otherwise, but they also have shortcomings: the former technique allows only indirect conclusions regarding synaptic connectivity patterns; and the second technique is tedious and time consuming, and thus not well suited to describe connectivity patterns quantitatively.

Received November 23, 2015; accepted July 15, 2016; First published July 21, 2016.

The authors declare no competing financial interests.

Author contributions: J.B. and J.R.H. designed research; J.B., J.M., and J.R.H. performed research; K.D. contributed unpublished reagents; J.B., J.M., and J.R.H. analyzed data; J.B., J.M., and J.R.H. wrote the paper.

This research was supported by National Institutes of Health Grants NS-034774, NS-006477, and NS-012151.

Acknowledgments: We thank Isabel Parada and Charu Ramakrishnan for excellent technical assistance.

Correspondence should be addressed to John R. Huguenard, Department of Neurology and Neurological Sciences, Stanford University School of Medicine, 1050A Arastradero Road, Room A250, Palo Alto, CA 94304. E-mail: john.huguenard@stanford.edu.

DOI:http://dx.doi.org/10.1523/ENEURO.0142-15.2016

Copyright (C) 2016 Brill et al.

This is an open-access article distributed under the terms of the Creative Commons Attribution 4.0 International, which permits unrestricted use, distribution and reproduction in any medium provided that the original work is properly attributed.
A newer method for circuit mapping is the use of laser-scanning photostimulation (LSPS). In LSPS, caged glutamate [i.e., glutamate attached to a chemical moiety that renders it physiologically inert, most commonly 4-methoxy-7-nitroindolinyl (MNI)] is added to the artificial CSF (ACSF) bath. Brief ( $\sim 1 \mathrm{~ms})$ and highly focal pulses of UV light photolyze the bond between MNI and glutamate, thus "uncaging" it, and enabling it to act on cellular glutamate receptors. In neurons, only glutamate uncaging onto somata results in action potential generation, while uncaging onto dendrites generally generates subthreshold depolarizations. Thus, focal glutamate uncaging is a method to effectively map the somatic location of the presynaptic inputs of a recorded cell (Callaway and Katz, 1993; Dantzker and Callaway, 2000; Shepherd et al., 2003; Shepherd and Svoboda, 2005; Deleuze and Huguenard, 2006). Further, using two-photon uncaging onto GFP-tagged neurons has the advantage to restrict activation to specific genetically identified neuron types (Fino and Yuste, 2011; Packer and Yuste, 2011).

We developed complementary approaches to combine LSPS and optogenetic circuit mapping to examine PV-toPYR connectivity more quantitatively: first, we used AAV5-EF1 $\alpha$-DIO-hChR2(E123T)-eYFP (ChETA)-mediated focal excitation of PV cells to map PV-to-PYR inputs analogous to chemical LSPS, but with definite cell-type specificity. This allowed us to unambiguously map PV-toPYR connections and to identify them conclusively as short-latency inhibitory events. Second, we used LSPS combined with optogenetic silencing of PV cells to record synaptic input maps, and to demonstrate significant layerspecific expansion of excitatory maps under conditions of PV cell silencing. These results show that chemical LSPS with caged glutamate powerfully activates a form of synthetic "feedforward" inhibition that silences neurons, preventing their output, and thus obscuring their contribution to the resultant synaptic connectivity map. This confound must be taken into account in the context of interpreting LSPS-based circuit maps, as the synthetic feedforward inhibition will cause an underestimation of true connectivity. Any changes in the excitability of PV cells, for example in cortical injury (Brill and Huguenard, 2010), would alter the synthetic silencing and further complicate interpretation of altered connectivity maps.

\section{Materials and Methods}

\section{Animals}

All experiments were performed according to protocols approved by Stanford University Institutional Animal Care and Use Committee, and every precaution was taken to minimize stress and the number of animals used in each series of experiments. Parv::cre transgenic mice were obtained from The Jackson Laboratory. Male and female mice aged postnatal day 45-60 were used throughout the experiments.

\section{Opsin expression}

AAV5-EF1 $\alpha$-DIO-eNpHR3.0-EYFP (Gradinaru et al., 2008) and ChETA (Gunaydin et al., 2010) viruses were produced by the University of Carolina at Chapel Hill 
Vector Core. One microliter of virus (titer $10^{12} / \mu \mathrm{l}$ ) was stereotactically injected into bilateral primary somatosensory cortex of 25- to 30-d-old parv::cre mice under isoflurane anesthesia. Injection coordinates (relative to bregma) were as follows: dorsoventral, 0.7; mediolateral, \pm 1.6 ; anterioposterior, -0.5 .

\section{Preparation of acute neocortical slices}

Acute neocortical slices were prepared 2-4 weeks after virus injection. Mice were deeply anesthetized with 50 $\mathrm{mg} / \mathrm{kg}$ sodium pentobarbital, and brains were removed and immediately transferred into ice-cold sucrose solution, which contained the following (in mm): 234 sucrose, 11 glucose, $26 \mathrm{NaHCO}_{3}, 2.5 \mathrm{KCl}, 1.25 \mathrm{NaH}_{2} \mathrm{PO}_{4}, 10$ $\mathrm{MgSO}_{4}$, and $0.5 \mathrm{CaCl}_{2}$, equilibrated with $95 \% \mathrm{O}_{2} / 5 \%$ $\mathrm{CO}_{2}$. The $300 \mu \mathrm{m}$ coronal slices were sectioned on a VT $1200 \mathrm{~S}$ Vibratome (Leica) at $4^{\circ} \mathrm{C}$ in sucrose solution and transferred to a holding chamber filled with ACSF (in mм: $126 \mathrm{NaCl}, 26 \mathrm{NaHCO}_{3}, 2.5 \mathrm{KCl}, 1.25 \mathrm{NaH}_{3} \mathrm{PO}_{4}, 2 \mathrm{CaCl}_{2}, 2$ $\mathrm{MgCl}_{2}, 10$ glucose, equilibrated with $95 \% \mathrm{O}_{2} / 5 \% \mathrm{CO}_{2}, \mathrm{pH}$ 7.4). After a recovery period of $1 \mathrm{~h}$ at $32^{\circ} \mathrm{C}$, the holding chamber containing the slices was removed from the water bath and allowed to cool to room temperature.

\section{Electrophysiological recordings}

Slices were transferred to a recording chamber and constantly superfused with oxygenated ACSF at a rate of $\sim 2 \mathrm{ml} / \mathrm{min}$. Experiments were conducted at room temperature $\left(23-25^{\circ} \mathrm{C}\right)$ to avoid excessive evaporation of the relatively small volume $(30 \mathrm{ml})$ of recirculating ACSF containing caged glutamate. All cells recorded were located in the limb area of primary somatosensory cortex. Cortical layers were identified visually from an overview image obtained with a $5 \times$ objective and neurons were visualized with a $63 \times$ objective using differential contrast optics with an Axioskop 2 FS Microscope (Zeiss). Pyramidal cells were identified based on their large size, tear-shaped morphology, and thick apical dendrite. Opsin-expressing PV cells were identified and targeted based on their enhanced yellow fluorescent protein (eYFP) fluorescence. Recordings were obtained using borosilicate glass electrodes with a tip resistance of 2-4 $\mathrm{M} \Omega$. The pipette solution used for voltage-clamp and cell-attached recordings (excitation profiles) contained the following (in $\mathrm{mm}$ ): 130 Cs-gluconate, $8 \mathrm{CsCl}, 10 \mathrm{HEPES}, 4 \mathrm{EGTA}$, and 0.01 QX314, pH 7.3 adjusted with $\mathrm{CsOH}$ (290 mOsm). For current-clamp recordings, the following internal solution was used (in mM): $120 \mathrm{~K}$-gluconate, $11 \mathrm{KCl}, 1 \mathrm{MgCl}_{2}, 1$ $\mathrm{CaCl}_{2}, 10 \mathrm{HEPES}$, and $10 \mathrm{EGTA}$, and $\mathrm{pH} 7.3$ adjusted with $\mathrm{KOH}$ (290 mOsm). NMDA receptor-mediated currents were blocked by $50 \mu \mathrm{M}$ D-AP5 (Ascent Scientific). For recordings of IPSC maps, AMPA and NMDA receptors were blocked, and an internal solution was used that permitted recording IPSCs as inward currents at $-60 \mathrm{mV}$. It contained the following (in $\mathrm{mm}$ ): $70 \mathrm{~K}$-gluconate, $70 \mathrm{KCl}$, $2 \mathrm{NaCl}, 10$ HEPES, 10 EGTA, and 10 EGTA, pH 7.3 adjusted with $\mathrm{KOH}$ (290 mOsm). Only recordings in which the series resistance was $<25 \mathrm{M} \Omega$ and changed $<30 \%$ during the recording were included in the data analysis, and no series resistance compensation was used. Membrane potentials were corrected for a liquid junction po- tential of $15 \mathrm{mV}$, and all voltages given subsequently include liquid junction potential correction. Signals were amplified with a Multiclamp $700 \mathrm{~A}$ amplifier, sampled at $10 \mathrm{kHz}$, filtered at $3 \mathrm{kHz}$, acquired using a Digidata 1320A digitizer, and analyzed using pClamp9 and pClamp10 (all Molecular Devices). Electrical stimulation was performed using a bipolar concentric electrode (CB-X RC75, Frederick Haer).

\section{Laser-scanning photostimulation/glutamate uncaging}

For focal photolysis of caged glutamate, a pulsed 355 $\mathrm{nm}$ UV laser beam (DPSS Lasers) was launched into a multimode fiber optic cable and collimated at its output (Oz Optics) then directed via scanning optics into the back aperture of the 5 or $63 \times$ microscope objective, so that it could be directed to any point visible through the objective. Scanning was controlled with mirror galvanometers (Model 6210, Cambridge Technology) using a locally developed software program. The beam half-width was $\sim 130 \mu \mathrm{m}$ at $5 \times$. Focal photolysis of MNI-caged glutamate (Tocris Bioscience; $100 \mu \mathrm{M}$ ) was triggered by $50 \mathrm{~mW}$ UV light pulses (300-800 $\mu \mathrm{s})$. MNI-caged glutamate was supplied in a $30 \mathrm{ml}$ recirculating bath solution. Typically, the bath solution was exchanged after 3-4 h or sooner if significant rundown of direct responses was detected.

\section{Optical stimulation}

Light produced by a xenon arc lamp (Oligochrome, TILL Photonics) was filtered through a $593 \pm 25 \mathrm{~nm}$ bandpass filter (FF01-593/40-25, Semrock) and directed into the epifluorescence port of the microscope for full-field illumination. To allow for simultaneous UV illumination (see Fig. $3 A$, diagram), yellow light was reflected using a custom short-pass dichroic mirror [Semrock (similar to SP01532RU)] that reflected yellow light $(593 \mathrm{~nm})$, but passed UV and blue wavelengths (355 and $472 \mathrm{~nm}$, respectively). Alternatively, a blue laser (473 nm; OEM Laser Systems) was scanned onto the slice as described for laser scanning LSPS, using the same Oz Optics multimode optical fiber.

\section{Synaptic input maps}

Using our locally developed software program, we defined areas to be scanned, along with the number of grid points for LSPS within that area (number of rows and columns). Maps spanned all cortical layers with a grid spacing of $90-100 \mu \mathrm{m}$. Points were stimulated in a pseudorandom pattern designed to minimize sequential activation of adjacent grid points, with $5 \mathrm{~s}$ between stimuli. To isolate EPSC input, maps were recorded at a holding potential of $-60 \mathrm{mV}$, near the chloride equilibrium potential. Direct glutamatergic currents are recorded when glutamate is released onto the recorded cell. These responses consistently have an onset latency of $<3 \mathrm{~ms}$ and were distinguished from EPSCs on that basis (Brill and Huguenard, 2008). IPSC maps were recorded at $-5 \mathrm{mV}$, close to the reversal potential for AMPA receptormediated currents. To construct maps, we determined the cumulative amplitude of PSCs with onset latencies of 3-25 ms (EPSCs) and 2-50 ms (IPSCs) after the stimulus for each sweep. The cumulative amplitude is the sum of the amplitudes of all PSCs recorded within the detection 
time window and therefore represents a compound measure of event frequency and amplitude. To reduce the confounding effects of polysynaptic activation, NMDA receptors were blocked and a short detection window of 25 ms was used. PSCs were detected using locally written software. We then corrected the cumulative amplitude for the expected spontaneous activity in the equivalent time window. Spontaneous activity was determined for each cell for $1.5 \mathrm{~s} / \mathrm{sweep}$ during the interstimulus intervals starting $500 \mathrm{~ms}$ after each photostimulation. Averaged maps derived from all individual maps were obtained by using exact measurements of the $x$ and $y$ distances of each stimulation point from the reference point (soma or layer $1 / 2$ border) and then binning these at $100 \mu \mathrm{m}$ intervals. Smooth contours were derived by linear interpolation between $100 \mu \mathrm{m}$ bins.

\section{Immunohistochemistry}

Paraformaldehyde fixed and cryoprotected tissue was frozen and cut into $40 \mu \mathrm{m}$ sections on a HM 400 Cryotome (Microm). Sections were blocked in PBS and $10 \%$ normal goat serum for $1 \mathrm{~h}$ at room temperature, and incubated in primary antibody overnight at $4^{\circ} \mathrm{C}$ (mouse anti-parvalbumin; 1:1000; Sigma-Aldrich). Sections were rinsed twice at room temperature for $5 \mathrm{~min}$ and then incubated in solution containing fluorescent secondary antibody at room temperature for $1 \mathrm{~h}$ (goat anti-mouse IgG Alexa Fluor 568; $2 \mu \mathrm{g} / \mathrm{ml}$; Invitrogen). After rinsing twice in PBS for 5 min, sections were mounted on SuperfrostPlus slides (Fisher Scientific) and coverslipped using Vectashield Mounting Medium (Vector Laboratories). Images were captured on a LSM 510 Confocal Laser Scanning Microscope (Zeiss).

\section{Statistical analysis}

Error bars reflect SEMs. Statistical significance was calculated using paired or unpaired Student's $t$ tests as appropriate.

\section{Results}

\section{Opsin expression and functionality}

Robust eYFP expression was observed 2 weeks after injection (Fig. 1A). eYFP expression was observed up to $0.5-1 \mathrm{~mm}$ from the injection site. A total of $55.8 \%$ of parvalbumin-positive cells within $0.3 \mathrm{~mm}$ of the injection site expressed viral protein, as quantified by the presence of eYFP fluorescence, while $\sim 97 \%$ of eYFP-expressing cells were parvalbumin-positive $(n=5$ slices from three animals; Fig.1B). This demonstrated high infection efficiency and specificity.

Photocurrents in response to yellow illumination were readily evoked from PV cells expressing eNpHR3.0 (halorhodopsin); the mean peak photocurrent was $242 \pm 63$ $\mathrm{pA}(n=17$; Fig. $1 C)$, which, given a mean input resistance of $164 \pm 36 \mathrm{M} \Omega(n=13)$, corresponded to a calculated hyperpolarization of the membrane potential of $25 \pm 9$ $\mathrm{mV}$. eNpHR3.0-evoked hyperpolarization blocked action potentials over a wide range of depolarizing current injections, and slowed spike frequency at higher injected currents (Fig. 1D). In ChETA-expressing PV cells, blue illumination elicited mean peak and steady-state photocurrents of $515 \pm 95$ and $369 \pm 85 \mathrm{pA}$, respectively $(n=$ 5; Fig. 1E). Rheobase (i.e., the minimum current needed for suprathreshold depolarization) for PV cells in our experiments was $123 \pm 21 \mathrm{pA}$ (range, $50-250 \mathrm{pA} ; n=11$ cells from five animals); thus, the evoked photocurrent would easily drive action potentials. Indeed, repeated 5 ms flashes of blue light delivered at a frequency of $100 \mathrm{~Hz}$ reliably evoked spikes in PV cells $(n=3$; Fig. $1 F)$.

\section{Direct mapping of inputs from ChETA-expressing PV cells onto PYRs}

We used focal blue illumination to excite ChETAexpressioning PV cells, and recorded the light-evoked IPSCs in PYRs (Fig. 2C). Analogous to LSPS with glutamate uncaging (see above), illumination could be directed quickly and in random order to any position on a userdefined grid within the area visible under the microscope objective. Figure $1 H$ shows a representative light-evoked IPSC in a PYR. Traces were recorded at $-60 \mathrm{mV}$ using a high-chloride internal solution and ionotropic glutamate receptors were blocked (see Materials and Methods). To map synaptic inputs in a similar way as in LSPS/glutamate uncaging, we needed to determine the direct excitation profile of ChETA-expressing PV cells. Specifically, in chemical LSPS, action potentials are almost exclusively evoked when glutamate is uncaged directly onto the soma or proximal apical dendrite of the cell (Shepherd et al., 2003; Deleuze and Huguenard, 2006), while uncaging on dendrites causes subthreshold depolarizations. However, it is well known that suprathreshold depolarizations can readily be evoked in opsin-expressing axons, and this feature is in fact exploited when characterizing the features or functions of specific synaptic inputs onto a given cell type (Paz et al., 2011; Yizhar et al., 2011; Mattis et al., 2014). Using a relatively low stimulation intensity $(\sim 1 \mathrm{~mW})$ favored somatic over axonal sites of suprathreshold depolarization. Thus, that focal optogenetic stimulation will include the somatic location but may not be entirely limited to it. In the case of ChETA-expressing PV cells, optogenetically evoked suprathreshold depolarizations were restricted to the area surrounding the soma $(n=4$; Fig. 1G), very similar to the situation in LSPS/ glutamate uncaging. With that, we were able to map the location of PV cells that projected onto layer 5 PYRs, although a possible contribution from direct axonal activation cannot be excluded (see Discussion).

We typically mapped PV cell inputs onto PYRs from 1 $\mathrm{mm}^{2}$ squares using $0.1 \mathrm{~mm}$ grid spacing, with the recorded PYR being at the center of the square. Figure $2 A$ shows a representative grid and Figure $2 B$ depicts example traces recorded at designated grid spots. Most IPSCs were evoked at very short latencies poststimulus (Fig. 2C). The poststimulus time histogram in Figure $2 D$ illustrates that virtually all evoked IPSCs arose within $10 \mathrm{~ms}$ of the light stimulus, which is consistent with the short latency to spike of PV cells (Brill and Huguenard, 2009). Similar to results obtained with two-photon LSPS targeting PV cells (Packer and Yuste, 2011), synaptic inputs originated close to the somata of recorded cells, as seen in the example 
A
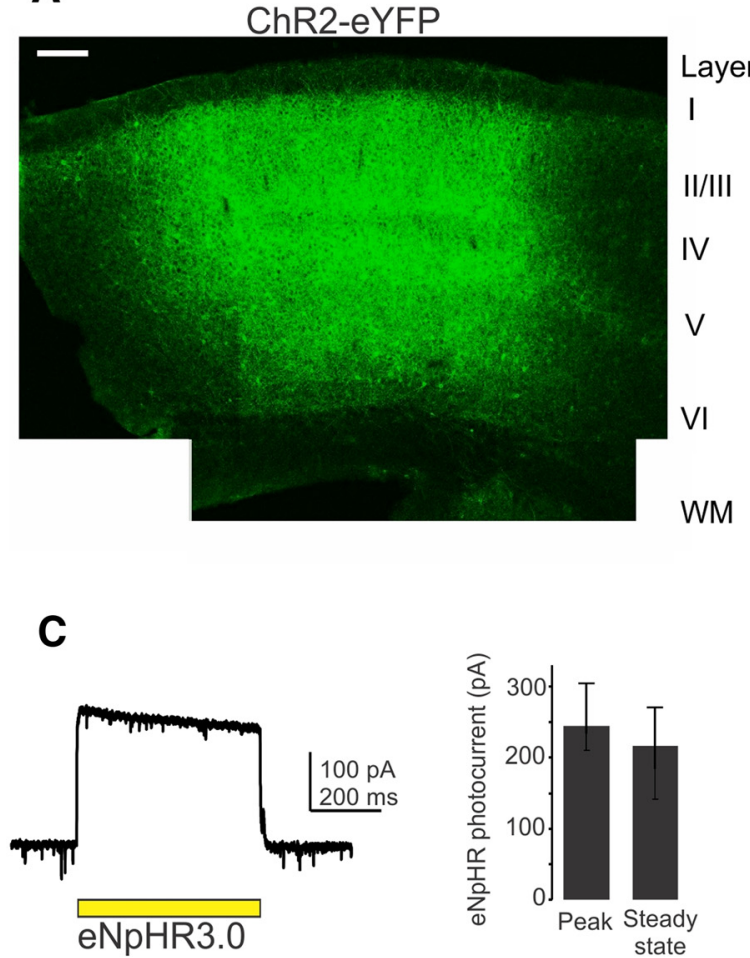

E

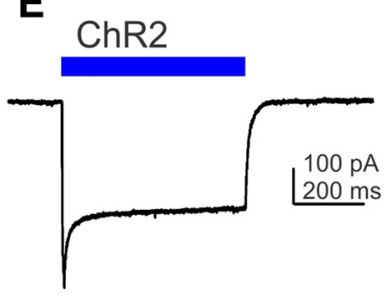

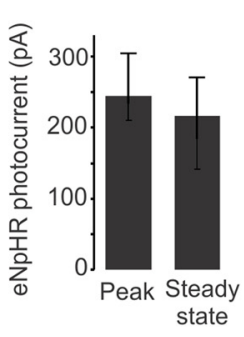

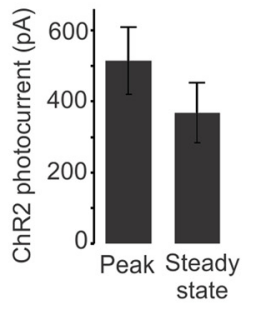

state
B
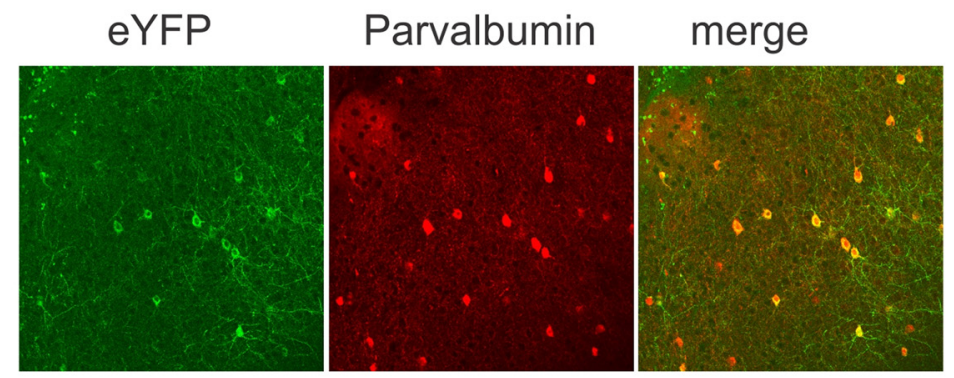

D

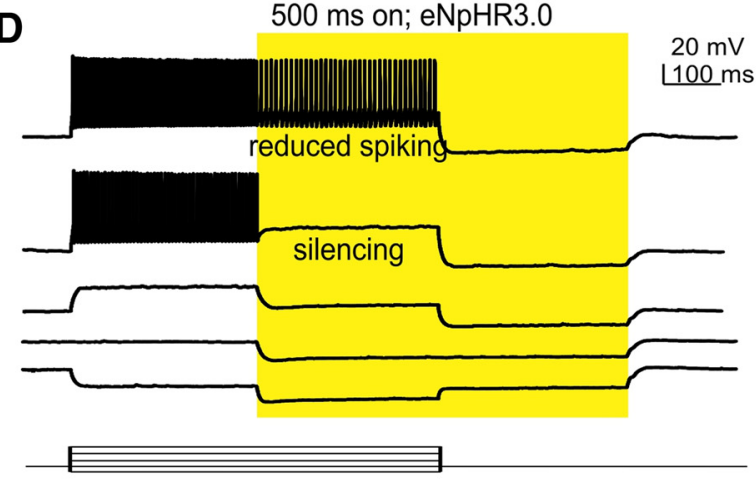

G

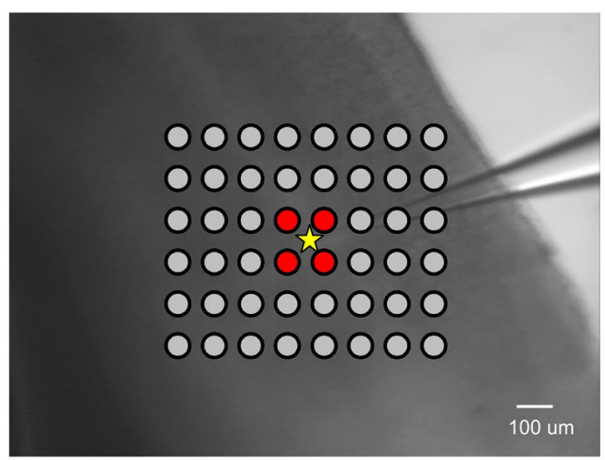

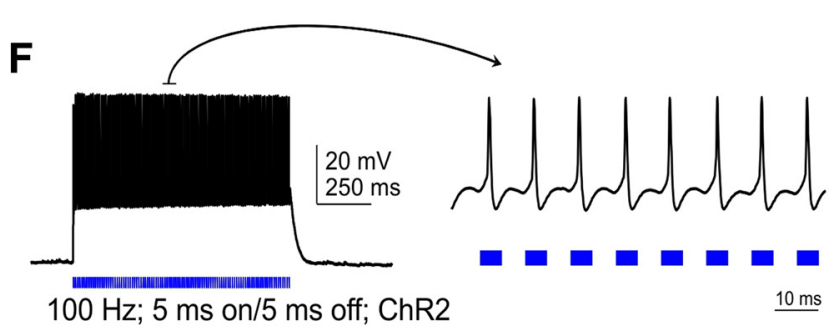

H

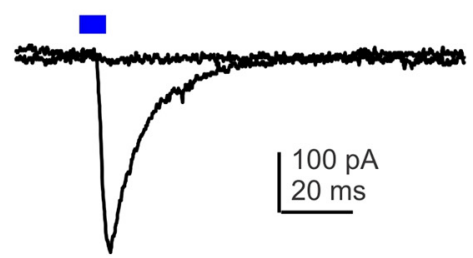

Figure 1. Opsin expression. A, eYFP expresion 3 weeks after virus injection in somatosensory cortex of a P40 mouse. Scale bar, 500 $\mu \mathrm{m}$. Location of cortical layers and white matter (WM) is indicated. $\boldsymbol{B}$, Overlapping eYFP and parvalbumin expression demonstrates correct targeting of the viral construct to PV cells. Scale bar, $100 \mu \mathrm{m}$. C, Direct eNpHR3.0 current in a PV cell. The yellow bar indicates illumination. $\boldsymbol{D}$, eNpHR3.0 activation decreases spike output in response to depolarizing current injections (yellow shading, yellow light is turned on). $\boldsymbol{E}$, Direct ChETA current in a PV cell. The blue bar indicates illumination. $\boldsymbol{F}$, Current-clamp response showing that PV cells can be driven by ChETA at $100 \mathrm{~Hz}(5 \mathrm{~ms}$ pulse width). The blue bar indicates illumination. G, Stimulation grid surrounding a recorded PV cell (yellow star represents soma location). Red grid points indicate where action potentials were generated in the recorded cell. $\boldsymbol{H}$, Example traces from a PYR recording showing success and failure in evoking an IPSC in successive trials, demonstrating the all-or-nothing nature of the evoked synaptic response. 
A

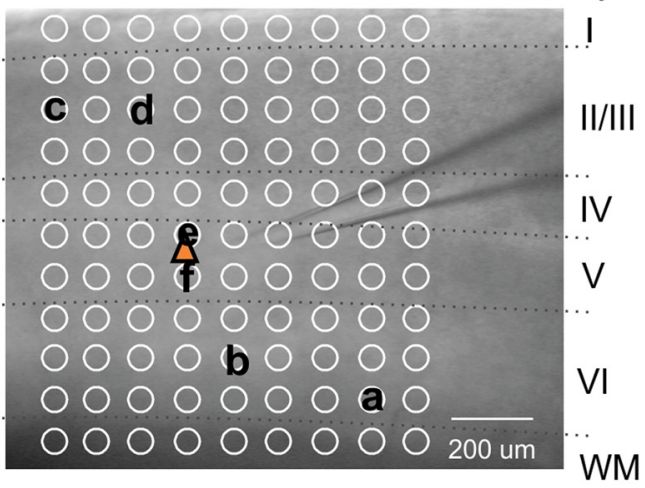

C

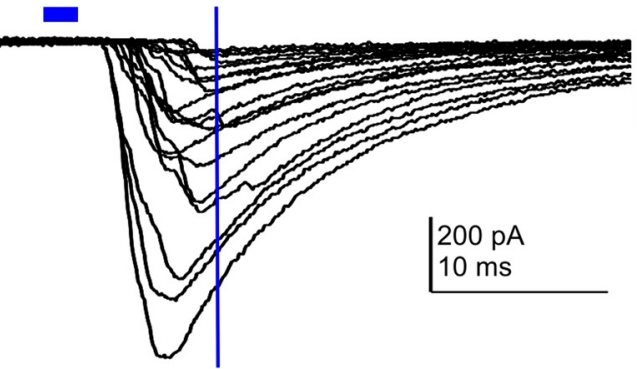

\section{Pia}

E

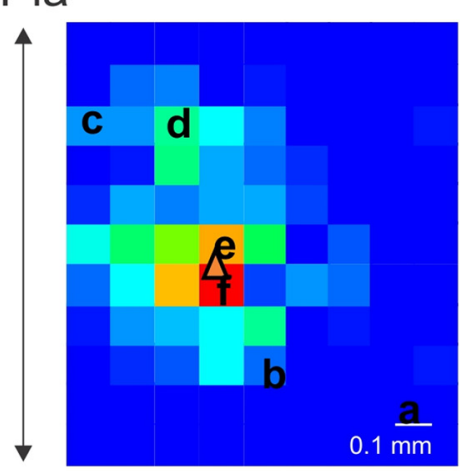

Layer

$\mid / I I I$

$\mathrm{V}$

$\sqrt{20}$

$\mathrm{VI}$

WM

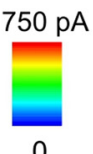

B

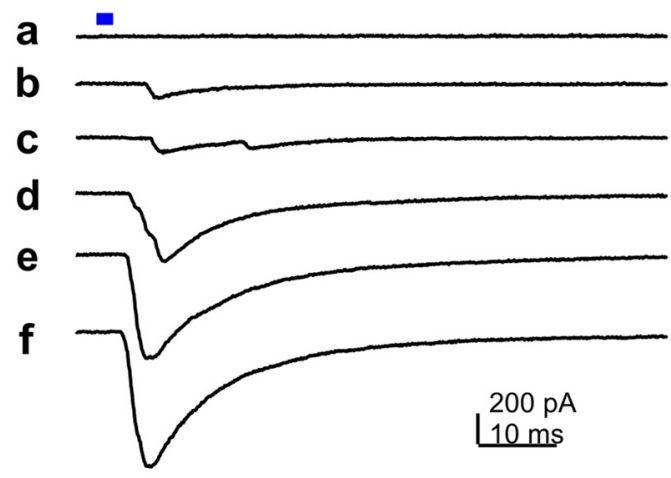

D

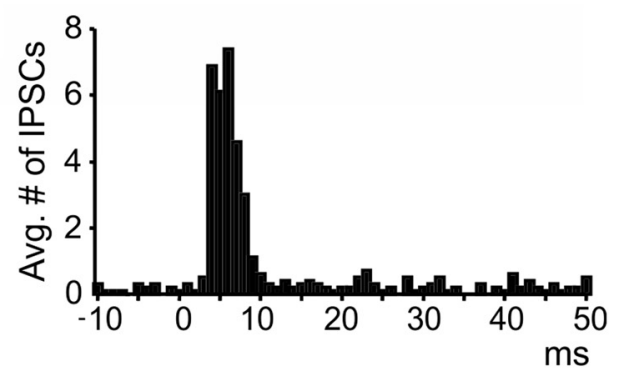

$\mathbf{F}$

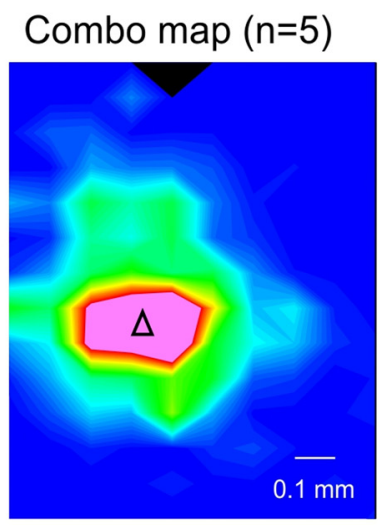

\section{White matter}

Figure 2. PV-to-PYR connectivity maps. $\boldsymbol{A}$, Representative grid for recording focal optogenetically evoked IPSCs in a PYR (yellow triangle indicates soma location). Location of cortical layers and white matter is indicated. $\boldsymbol{B}$, Example traces from the grid in $\boldsymbol{A}$, at indicated locations. The blue bar indicates the time of stimulus. $\boldsymbol{C}$, All traces with IPSC responses from the cell in $\boldsymbol{A}$ and $\boldsymbol{B}$. The blue horizontal line indicates stimulus time, the blue vertical line indicates $10 \mathrm{~ms}$ poststimulus. Note that nearly all IPSCs have a latency of $<10 \mathrm{~ms}$. $\boldsymbol{D}$, Peristimulus time histogram for IPSCs in all recorded PYRs. $\boldsymbol{E}$, IPSC map from example cell. $\boldsymbol{F}$, Averaged IPSC map from all recorded PYRs $(n=6)$.

cell (Fig. 2E), and a summary plot ( $n=5$ cells from three animals; Fig. 2F). These maps are highly similar to shortlatency IPSC input maps and thus confirm that they represent PV-to-PYR inputs (Brill and Huguenard, 2009).

\section{Mapping PV-to-PYR inputs using PV cell silencing and LSPS}

Next, we tested whether PV-to-PYR connectivity could be mapped indirectly using a combined approach of opto- genetic silencing of eNpHR3.0-expressing PV cells and LSPS. To that end, we directed yellow light (593 nm) through the epifluorescence port of the microscope for full-field illumination via the $63 \times$ or $5 \times$ objective. The UV light needed for LSPS was directed into the light path prior to the epifluorescence port and transmitted to the objective via a specialized short-pass dichroic mirror (see Materials and Methods). The beam of UV light could be directed to any part of the slice visible through the objec- 
tive via a pair of Galvo mirrors (Fig. $3 A$ ). Figure $3 B$ shows a cell-attached recording of an eNpHR3.0-expressing layer $5 \mathrm{PV}$ cell (identified by its action potential waveform in cell-attached mode; Brill and Huguenard, 2009), which fires two action potentials in response to LSPS, when the UV light was directed to its soma. In the presence of yellow illumination (15 ms, starting $7 \mathrm{~ms}$ before LSPS stimulus), PV cell spiking was abolished (Fig. 3B, bottom). Figure $3 C$ shows the outline of an LSPS map of IPSCs in a representative pyramidal cell. Maps were recorded twice: once without and once with yellow illumination $(-5$ to $70 \mathrm{~ms}$ relative to UV pulse) to silence PV cells. Yellow illumination led to a substantial reduction in IPSCs recorded in the PYR (Fig. 3D, example traces). We separated input maps into IPSCs recorded between 2-10 and 10-50 ms after the LSPS stimulus, to segregate PV- and non-PV cell-mediated inputs, respectively (Brill and Huguenard, 2009). Indeed, in the example cell, short-latency IPSCs (2-10 ms) were almost completely eliminated in the presence of yellow illumination (Fig. $3 E$ ), while regularlatency inputs (10-40 ms; Fig. $3 F)$ were not. This was also true on the population level $(n=6$ cells from three animals; Fig. 4): short-latency IPSCs were significantly reduced when PV cells were silenced (cumulative IPSCs per hotspot; control, $34.02 \pm 5.97 \mathrm{pA}$; silenced, $13.11 \pm 1.76$ $\mathrm{pA} ; p<0.05)$, while regular latency IPSCs remained unchanged (control, $33.23 \pm 5.49 \mathrm{pA}$; silenced, $25.46 \pm$ $4.18 \mathrm{pA} ; p=0.116$ ). This provides further confirmation that PV-to-PYR connectivity exclusively provides strong, short-latency inhibition.

\section{Functional role of PV cell-mediated feedforward inhibition}

Having established that LSPS-activated PV-to-PYR connections can be efficiently silenced by eNpHR3.0mediated hyperpolarization of PV cells, we wanted to determine how feedforward EPSCs in PYRs are affected by PV cell silencing, which would likely increase PYR excitation and reveal occult connections. In a series of preliminary experiments, we used electrical stimulation in layer $2 / 3$ to determine whether yellow illumination of eNpHR3.0-expressing PV cells could alter functional output of PYRs in layer 5. When recorded at a holding potential of $-40 \mathrm{mV}$ electrical stimuli typically resulted in biphasic responses consisting of an early EPSC followed by an IPSC, the latter of which was abolished by yellow illumination (Fig. $5 A$ ). When giving trains of five electrical stimuli at $50 \mathrm{~Hz}$ and recording in current-clamp, yellow illumination (i.e., silencing of PV cells) increased action potential generation: while the success rate (fraction of stimuli resulting in spikes) was $0.41 \pm 0.08$ in control conditions, it was increased to $0.59 \pm 0.06$ with PV silencing ( $p<0.001 ; n=16$ cells from eight animals; Fig. $5 B, C)$. Thus, we show that PV cell silencing can significantly impact functional PYR output.

Next, we used the combined LSPS/optogenetics approach outlined above, but instead of IPSCs, we recorded EPSCs by holding PYRs at $-60 \mathrm{mV}$, very close to the chloride equilibrium potential. LSPS excitatory synaptic input maps were recorded under control conditions and in the presence of full-field yellow illumination (continually from $7 \mathrm{~ms}$ before until $60 \mathrm{~ms}$ after LSPS stimulus), and an EPSC detection window of 3-25 ms post-LSPS stimulus was used. Figure $6 A-C$ shows example traces from a map recorded in a representative layer 5 PYR with and without yellow illumination, and the resulting EPSC maps. Silencing of eNpHR3.0-expressing PV cells lead to an increase in excitatory inputs (Fig. 6B,C, example traces $\mathrm{c}$ and d). A peristimulus time histogram (Fig. 6D) shows the average number of EPSCs recorded during all sweeps in the 11 cells, normalized to control (no illumination) values. EPSC rates were transiently elevated following LSPS stimulus, but returned to baseline values within $10 \mathrm{~ms}$. This indicates that most of the detected LSPS-evoked EPSCs are monosynaptic. On the population level $(n=11$ cells from seven animals), silencing PV cells resulted in significant increases in LSPS-mediated EPSC input onto layer 5 PYRs, especially from layers $2 / 3$ (average cumulative EPSC per spot: control, $1.06 \pm 0.15 \mathrm{pA}$; silenced, $1.51 \pm$ $0.25 \mathrm{pA} ; p<0.05$ ) and layer 4 (control, $0.51 \pm 0.07$; silenced, $0.84 \pm 0.08 ; p<0.001$; Fig. $6 E, F$. We conclude that PV cell silencing can unmask excitatory monosynaptic inputs onto PYRs in a layer-specific manner.

\section{Discussion}

In this study, we outline two methods for obtaining cell type-specific synaptic input maps: first, using focal optogenetic activation of target cells (PV cells in this case) to map PV-to-PYR connections; and second, a combined approach of LSPS- and eNpHR3.0-mediated silencing of PV cells to observe direct and indirect effects on inhibitory and excitatory connectivity, respectively.

Using targeted focal activation of ChETA-expressing PV cells, we mapped PV-to-PYR inhibitory inputs. We previously showed that LSPS-evoked inhibitory inputs onto PYRs could be roughly subdivided into the following two classes (short-latency, high-amplitude inputs; and longerlatency, lower-amplitude inputs), and we hypothesized that those were mediated by PV and non-PV cells, respectively (Brill and Huguenard, 2009). Results from the ChETA-based mapping approach support this idea, as the location and latency of PV-to-PYR inputs were very similar to short-latency ISPCs. Our results are also consistent with connectivity maps acquired using two-photon LSPS to excite individual GFP-tagged PV cells (Packer and Yuste, 2011). We also noted essentially no longdistance short-latency inputs, indicating that there are no prominent long-range PV cell-mediated connections to layer 5 (unlike long-range connections from layer 5 to layer 2/3; Buchanan et al., 2012).

In a second set of experiments, we activated cells by conventional LSPS either with or without silencing of eNpHR3.0-expressing PV cells. In this approach, rather than directly measuring PV-to-PYR inputs, we identified them indirectly by deducing their influence on the overall map. Again, we were able to conclude that PV cellmediated inputs onto PYRs were of the short-latency variety and originated from the area surrounding the somata of the recorded PYRs. Since this indirect approach used LSPS for cell activation, it may have been a more 
A

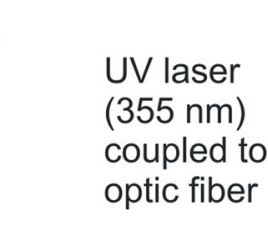



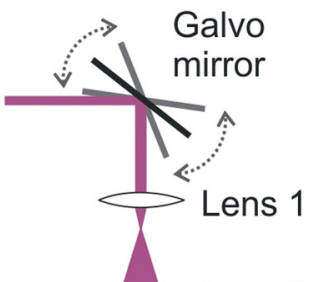

Xenon arc lamp, $590+/-20 \mathrm{~nm}$ bandpass filter

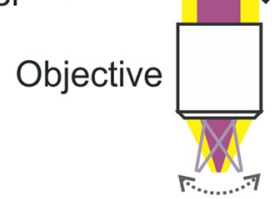

Slice
C

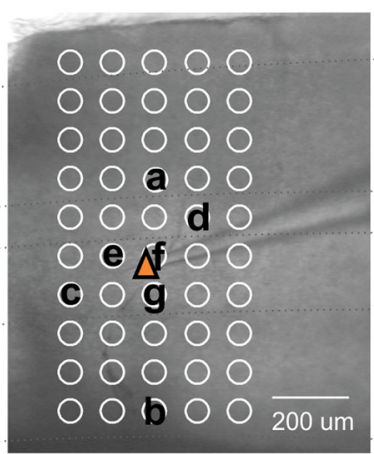

Layer

I

II/II

IV

V

VI

WM
E

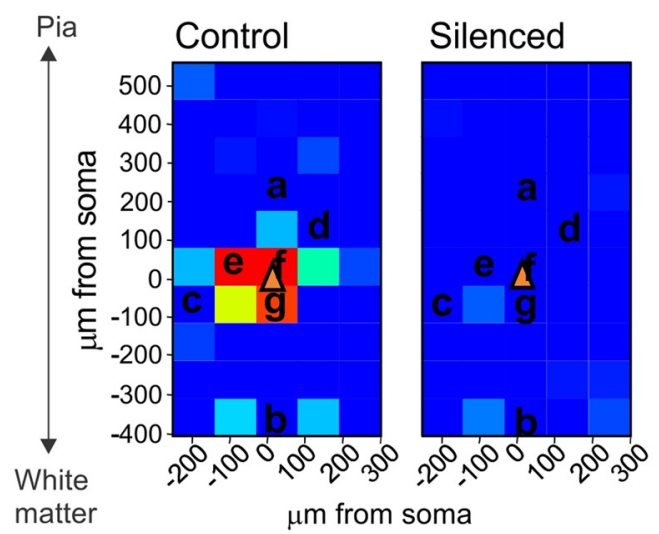

B

PV cell

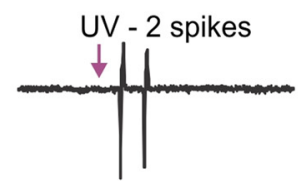

UV+silencing - no spikes

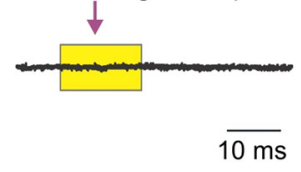

D

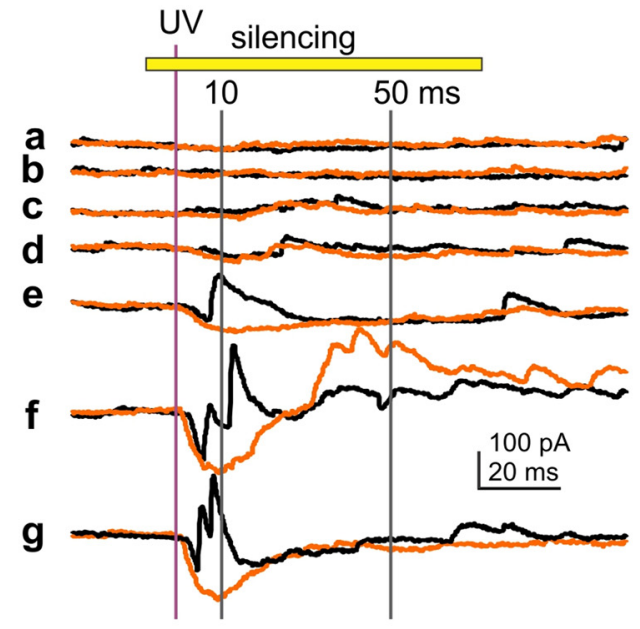

F

- Control - Silenced 10-50 ms
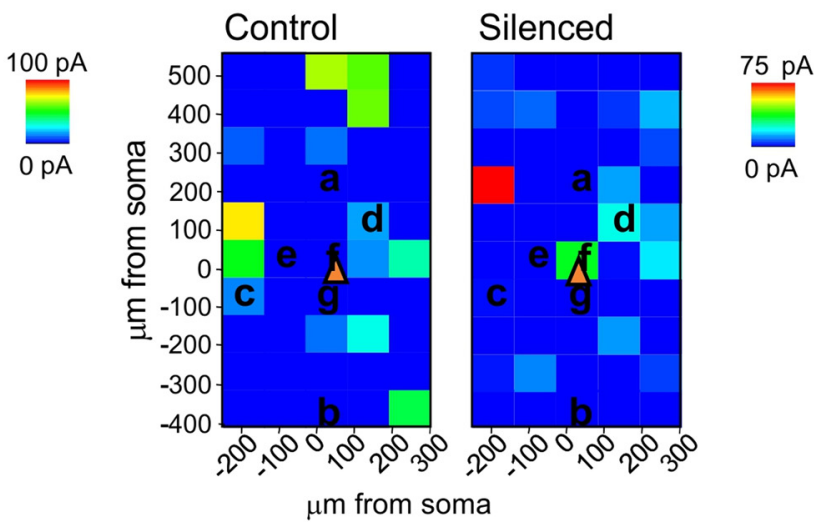

Figure 3. LSPS combined with eNphR-mediated PV cell silencing. A, Diagram depicting setup for LSPS and full-field yellow illumination. The yellow light is reflected by short-pass dichroic filter that transmits UV light. $\boldsymbol{B}$, Cell-attached recording of an opsin-expressing PV cell that is activated by LSPS only in the absence of eNphR-activating yellow illumination. $\boldsymbol{C}$, Representative grid for recording LSPS-evoked IPSCs (outward PSCs) in a PYR (orange triangle indicates soma location). Location of cortical layers and white matter is indicated. $\boldsymbol{D}$, Example traces from the grid in $\mathbf{C}$, at indicated locations. Black traces are without yellow illumination; orange traces are with yellow illumination. Inward responses, largest in perisomatic regions, mainly reflect the direct activation of postsynaptic ionotropic GluRs. The yellow bar indicates illumination. The purple line indicates stimulus onset; vertical lines indicate 10 and $50 \mathrm{~ms}$, the detection times for short- and regular-latency IPSCs. $\boldsymbol{E}$, Short-latency IPSC maps for the example PYR without (left) and with (right) yellow illumination to silence PV cells. $\boldsymbol{F}$, Same as $\boldsymbol{E}$, but for regular-latency ISPCs. 

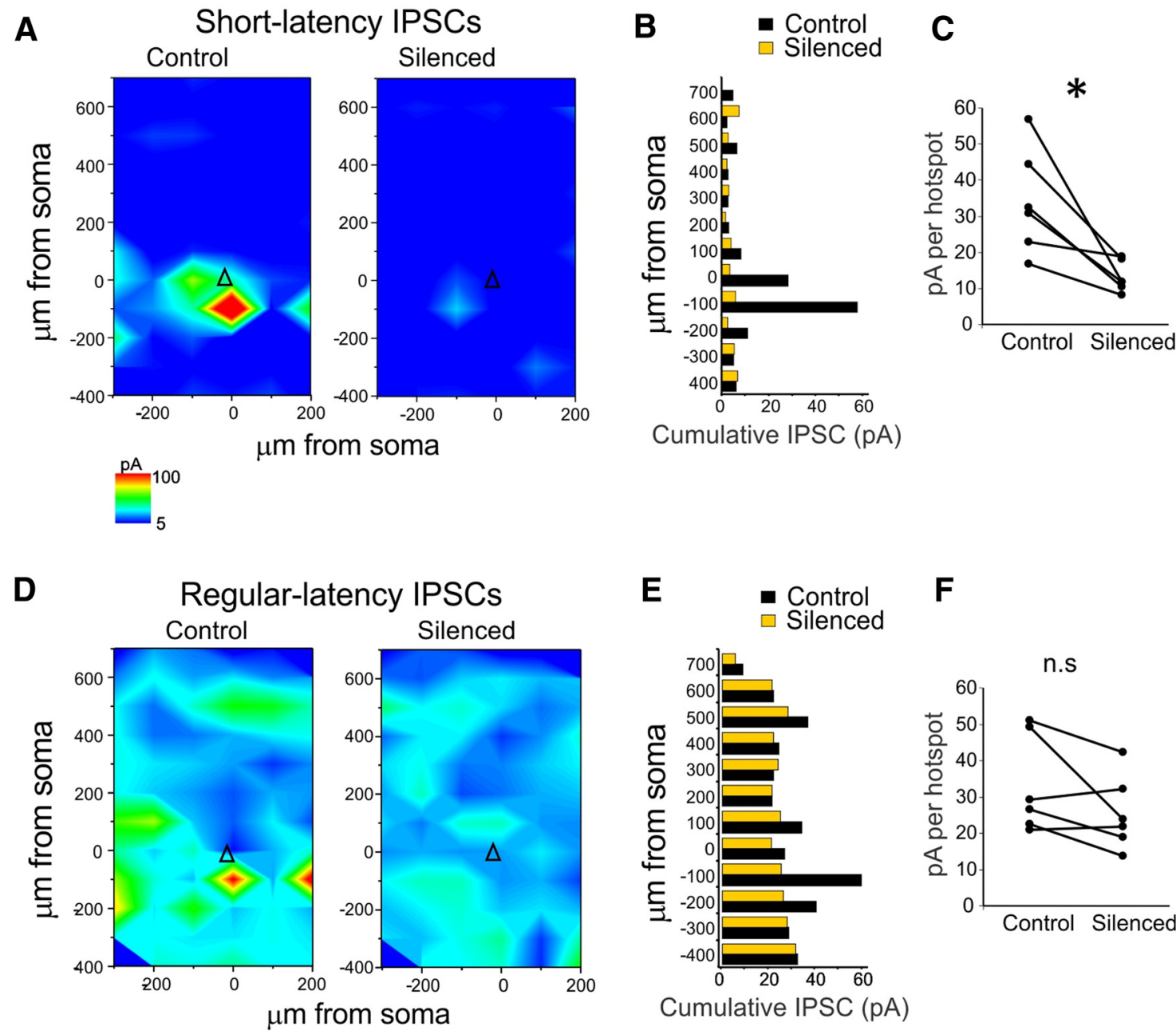

$\mathbf{F}$

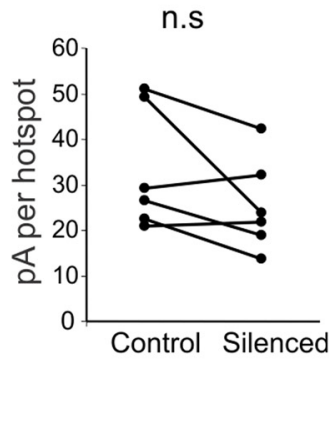

Figure 4. IPSC maps obtained via LSPS with and without PV cell silencing. $\boldsymbol{A}$, Summary maps for short-latency IPSC maps in PYRs (triangle indicates soma location) recorded without (left) and with (right) yellow illumination. $N=6$. $\boldsymbol{B}$, Cumulative IPSC amplitudes (in pA) relative to the horizontal distance from soma without (black) and with (yellow) yellow illumination. $\boldsymbol{C}$, Cumulative IPSC amplitude per hotspot for all six recorded maps, showing a significant decrease with PV cell silencing. $\boldsymbol{D}-\boldsymbol{F}$, Same as $\boldsymbol{A}-\boldsymbol{C}$, but for regular-latency IPSCs. No significant decrease in cumulative amplitude/hotspot with PV cell silencing $(\boldsymbol{F})$. * indicates statistical significance at $p<0.05$. n.s. $=$ non significant.

direct comparison to the original study (Brill and Huguenard, 2009) than the ChETA-based input mapping. This circumvents potential confounders such as the ability of channelrhodopsins to activate axons, which LSPS does


Figure 5. PV cell silencing affects EPSCs in PYRs. A, PSC in a PYR cell in response to electrical stimulation without (black trace) and with (orange trace) PV cell silencing. Note the absence of an IPSC with yellow illumination. $\boldsymbol{B}$, Response to trains of five electrical stimuli $(50 \mathrm{~Hz})$ in a PYR in current clamp without, with, and again without yellow illumination (top to bottom). Note two successes vs. one success of five stimuli with PV cell silencing. $\boldsymbol{C}$, Quantification of PYR disinhibition due to PV cell silencing, measured as the fraction of successes (action potentials) for five-pulse stimuli, as shown in $\boldsymbol{B}$. 
A



B

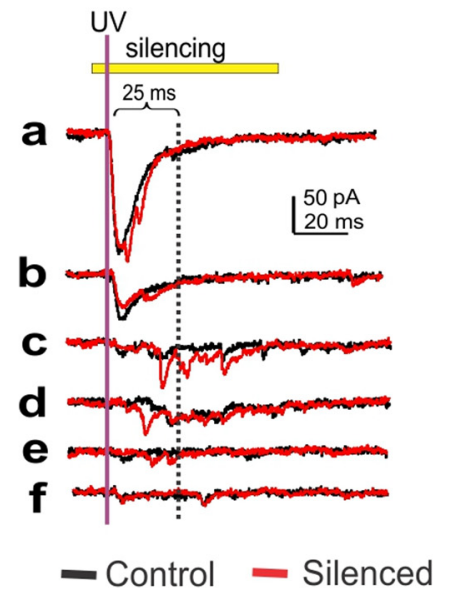

E



C

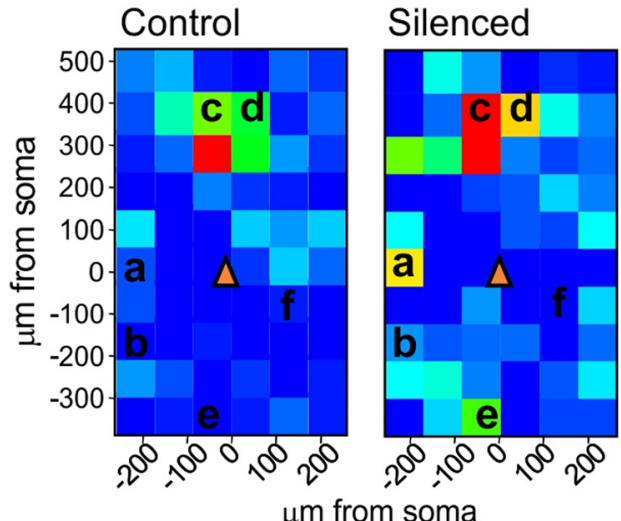

D

Layer
$\mathrm{I} \ldots . .$.

$\mathrm{V}$
$\mathrm{VI}$
$\mathrm{VI} / \mathrm{IV} \mathrm{.}$
$\mathrm{WM}$

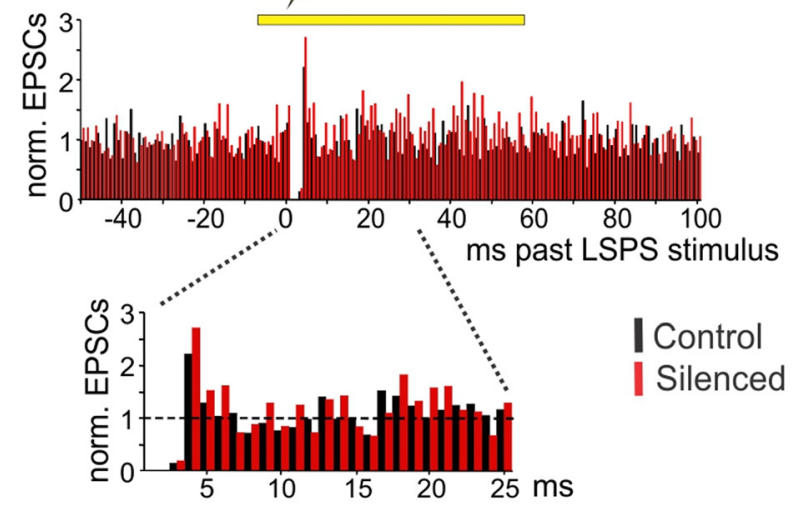

$\mathbf{F}$

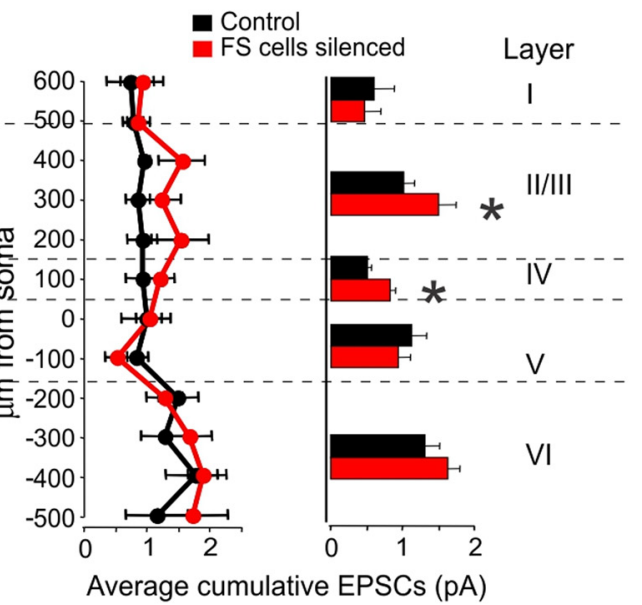

Figure 6. PV cell silencing unmasks excitatory connectivity. A, Representative grid for recording LSPS-evoked EPSCs in a PYR (yellow triangle indicates soma location). Location of cortical layers and white matter is indicated. $\boldsymbol{B}$, Example traces from the grid in $\boldsymbol{A}$, at indicated locations. Black traces are without yellow illumination, and red traces are with yellow illumination. Yellow bar indicates yellow illumination; purple line indicates UV stimulus; black line indicates 25 ms post-UV stimulus (end of EPSC detection window). $\boldsymbol{C}$, EPSC maps for the example PYR without (left) and with (right) yellow illumination to silence PV cells. D, Peristimulus time histogram for EPSCs recorded in 11 pyramidal cells. All detected EPSCs (spontaneous and LSPS evoked) during all sweeps from all 11 cells were sorted into $1 \mathrm{~ms}$ bins relative to LSPS stimulus and normalized to the average EPSC rate in controls (100 ms preceding LSPS stimulus). Black, Control (no yellow illumination); red, with PV cell silencing. EPSC rates are elevated following LSPS stimulus but return to baseline within $\sim 10 \mathrm{~ms}$, indicating that evoked EPSCs are predominantly monosynaptic. Bottom, Zoomed-in view of the 25 ms following LSPS stimulus, which were used as a detection window for evoked EPSCs. $E$, Summary EPSC maps in PYRs recorded without (left) and with (right) yellow illumination. $N=11$. $\boldsymbol{F}$, Cumulative EPSC amplitudes relative to the horizontal distance from soma in $100 \mu \mathrm{m}$ bins (left) and for each neocortical layer (right). $*$ indicates statistical significance at $p<0.05$. 
not (see above). It is of interest to note that the LSPS study that identified short-latency versus regular-latency inputs used neocortical slices from rats (Brill and Huguenard, 2009), while the present study was done using mice. We conclude that the focal and dynamic profiles of PVto-PYR connectivity in both species of rodents are quite similar. Since not all PV cells were infected with opsins (Fig. 1), residual short-latency IPSCs might stem from uninfected (non-eNpHR3.0-expressing) PV cells.

Both of these approaches (direct ChETA-based input mapping and LSPS/eNpHR3.0-based mapping) can be used to construct input maps between any two cell types, thus facilitating medium-/high-throughput, cell type-specific quantitative connectivity mapping. Using a soma- or axon initial segment-targeting channelrhodopsin variant (Grubb and Burrone, 2010) would enhance the spatial specificity of the direct approach. We should also caution that a response to glutamate uncaging or optogenetic stimulation indicates the presence of a presynaptic cell, but that the lack of a response does not indicate the lack of a presynaptic cell. Our methods thus make a statistical argument for connectivity patterns, but do not identify connections exhaustively.

We also recorded excitatory LSPS-evoked inputs in the presence and absence of eNpHR3.0-mediated PV cell silencing. We show that PV cell silencing unmasks significant, layer-specific EPSC inputs. Leading into this set of experiments, we also demonstrate that PV cell silencing increases the spike output of PYRs when subjected to a train of electrical stimuli. We assume that the mechanism that accounts for this effect is the following: electrical stimulation activates not only axons of excitatory cells that target the recorded PYRs, but also those of local interneurons. Under control conditions, suprathreshold and rapid activation of PV cells in proximity of the PYRs results in a recurrent inhibition in those PYRs that is powerful enough to suppress their direct excitation and action potential output by uncaged glutamate. When this inhibition is silenced, PYR spike output increases.

Focal LSPS with PV cell silencing likely relies on PV-toPYR feedforward inhibition, too. For excitatory inputs to be received by the recorded PYR (located elsewhere), PV-to-PYR feedforward inhibition must be overcome at the LSPS stimulation site. When subjected to LSPS of equal intensity, PV cells have significantly shorter spike latencies than PYRs (Brill and Huguenard, 2009); thus, it is plausible that the simultaneous activation of PYRs and PV cells by LSPS still results in significant functional feedforward inhibition of PYRs. Notably, the strength of this feedforward inhibition appears to vary between cortical layers, as it is especially prominent in upper layers.

Our results show that PV cell activity can effectively occlude excitatory connectivity between PYRs. In other words, the silencing of PV cells reveals many occult connections that were masked by powerful feedforward inhibition. This is especially relevant for studies comparing excitatory connectivity during development or in disease models. For example, epilepsy/hyperexcitability is frequently characterized by increased excitatory connectivity as a result of axonal sprouting (for review, see Marco and deFelipe, 1997; Jin et al., 2006; Chu et al., 2010; Zhang et al., 2012; Buckmaster, 2014; Kúsmierczak et al., 2015), but changes in inhibitory connectivity have also been reported (Brill and Huguenard, 2010; Zhou and Roper, 2010; Jin et al., 2011, 2014). When quantifying excitatory connectivity changes, one should bear in mind that decreased interneuron excitability or interneuron loss might enhance net excitatory inputs due to a lack of feedforward inhibition, and vice versa. The ultimate "clean" experiment would be to record EPSC input in the presence of GABAergic blockers; but, unfortunately, this will rarely be possible due to the emergence of epileptiform activity in fully disinhibited slices (Chagnac-Amitai and Connors, 1989). Brief disinhibition of only a subset of interneurons, as described here, can circumvent this problem, as we did not observe epileptiform activity during our experiments.

Using opsin-expressing interneuron subtypes as a tool for synaptic connectivity mapping alone or in combination with LSPS is a promising way to obtain quantitative information on interneuron connectivity patterns. It can also shed light on phenomena such as feedforward inhibition and its impact on connectivity mapping.

\section{References}

Bannister AP, Thomson AM (2007) Dynamic properties of excitatory synaptic connections involving layer 4 pyramidal cells in adult rat and cat neocortex. Cereb Cortex 17:2190-2203. CrossRef Medline

Bock DD, Lee WC, Kerlin AM, Andermann ML, Hood G, Wetzel AW, Yurgenson S, Soucy ER, Kim HS, Reid RC (2011) Network anatomy and in vivo physiology of visual cortical neurons. Nature 471:177-182. CrossRef Medline

Brill J, Huguenard JR (2008) Sequential changes in AMPA receptor targeting in the developing neocortical excitatory circuit. J Neurosci 28:13918-13928. CrossRef Medline

Brill J, Huguenard JR (2009) Robust short-latency perisomatic inhibition onto neocortical pyramidal cells detected by laser-scanning photostimulation. J Neurosci 29:7413-7423. CrossRef Medline

Brill J, Huguenard JR (2010) Enhanced infragranular and supragranular synaptic input onto layer 5 pyramidal neurons in a rat model of cortical dysplasia. Cereb Cortex 20:2926-2938. CrossRef Medline

Buchanan KA1, Blackman AV, Moreau AW, Elgar D, Costa RP, Lalanne T, Tudor Jones AA, Oyrer J, Sjöström PJ (2012) Targetspecific expression of presynaptic NMDA receptors in neocortical microcircuits. Neuron 75:451-466. CrossRef

Buckmaster PS (2014) Does mossy fiber sprouting give rise to the epileptic state? Adv Exp Med Biol 813:161-168. CrossRef Medline

Callaway EM, Katz LC (1993) Photostimulation using caged glutamate reveals functional circuitry in living brain slices. Proc Natl Acad Sci U S A 90:7661-7665. Medline

Chagnac-Amitai Y, Connors BW (1989) Horizontal spread of synchronized activity in neocortex and its control by GABA-mediated inhibition. J Neurophysiol 61:747-758. Medline

Chu Y, Jin X, Parada I, Pesic A, Stevens B, Barres B, Prince DA (2010) Enhanced synaptic connectivity and epilepsy in C1q knockout mice. Proc Natl Acad Sci U S A 107:7975-7980. CrossRef Medline

Dantzker JL, Callaway EM (2000) Laminar sources of synaptic input to cortical inhibitory interneurons and pyramidal neurons. Nat Neurosci 3:701-707. CrossRef Medline

Deleuze C, Huguenard JR (2006) Distinct electrical and chemical connectivity maps in the thalamic reticular nucleus: potential roles in synchronization and sensation. J Neurosci 26:8633-8645. CrossRef Medline 
Fino E, Yuste R (2011) Dense inhibitory connectivity in neocortex. Neuron 69:1188-1203. CrossRef Medline

Freund TF, Katona I (2007) Perisomatic inhibition. Neuron 56:33-42. CrossRef Medline

Gradinaru V, Thompson KR, Deisseroth K (2008) eNpHR: a Natronomonas halorhodopsin enhanced for optogenetic applications. Brain Cell Biol 36:129-139. CrossRef Medline

Grubb MS1, Burrone J (2010) Channelrhodopsin-2 localised to the axon initial segment. PLoS One 5:e13761 CrossRef Medline

Gunaydin LA, Yizhar O, Berndt A, Sohal VS, Deisseroth K, Hegemann P (2010) Ultrafast optogenetic control. Nat Neurosci 13:387-392. CrossRef Medline

Jin X, Prince DA, Huguenard JR (2006) Enhanced excitatory synaptic connectivity in layer $\mathrm{V}$ pyramidal neurons of chronically injured epileptogenic neocortex in rats. J Neurosci 26:4891-4900. CrossRef

Jin X, Huguenard JR, Prince DA (2011) Reorganization of inhibitory synaptic circuits in rodent chronically injured epileptogenic neocortex. Cereb Cortex 21:1094-1104. CrossRef Medline

Jin X, Jiang K, Prince DA (2014) Excitatory and inhibitory synaptic connectivity to layer $\mathrm{V}$ fast-spiking interneurons in the freeze lesion model of cortical microgyria. J Neurophysiol 112:1703-1713. CrossRef Medline

Kúsmierczak M, Lajeunesse F, Grand L, Timofeev I (2015) Changes in long-range connectivity and neuronal reorganization in partial cortical deafferentation model of epileptogenesis. Neuroscience 284:153-164. CrossRef Medline

Kepecs A, Fishell G (2014) Interneuron cell types are fit to function. Nature 505:318-326. CrossRef Medline

Lourenço J, Pacioni S, Rebola N, van Woerden GM, Marinelli S, DiGregorio D, Bacci A (2014) Non-associative potentiation of perisomatic inhibition alters the temporal coding of neocortical layer 5 pyramidal neurons. PLoS Biol 12:e1001903 CrossRef Medline

Mattis J, Brill J, Evans S, Lerner TN, Davidson TJ, Hyun M, Ramakrishnan C, Deisseroth K, Huguenard JR (2014) Frequencydependent, cell type-divergent signaling in the hippocamposeptal projection. J Neurosci 34:11769-11780. CrossRef Medline

Marco P, DeFelipe J (1997) Altered synaptic circuitry in the human temporal neocortex removed from epileptic patients. Exp Brain Res 114:1-10. Medline

Marin-Padilla M (1970) Prenatal and early postnatal ontogenesis of the human motor cortex: a Golgi study. II. The basket-pyramidal system. Brain Res 23:185-191. Medline

Murayama M, Pérez-Garci E, Nevian T, Bock T, Senn W, Larkum ME (2009) Dendritic encoding of sensory stimuli controlled by deep cortical interneurons. Nature 457:1137-1141. CrossRef Medline

Packer AM, Yuste R (2011) Dense, unspecific connectivity of neocortical parvalbumin-positive interneurons: a canonical microcircuit for inhibition? J Neurosci 31:13260-13271. CrossRef Medline
Packer AM, McConnell DJ, Fino E, Yuste R (2013) Axo-dendritic overlap and laminar projection can explain interneuron connectivity to pyramidal cells. Cereb Cortex 23:2790-2802. CrossRef Medline

Paz JT, Bryant AS, Peng K, Fenno L, Yizhar O, Frankel WN, Deisseroth K, Huguenard JR (2011) A new mode of corticothalamic transmission revealed in the Gria4(-/-) model of absence epilepsy. Nat Neurosci 14:1167-1173. CrossRef Medline

Qi G, Radnikow G, Feldmeyer D (2015) Electrophysiological and morphological characterization of neuronal microcircuits in acute brain slices using paired patch-clamp recordings. J Vis Exp 95: 52358.

Rudy B, Fishell G, Lee S, Hjerling-Leffler J (2011) Three groups of interneurons account for nearly $100 \%$ of neocortical GABAergic neurons. Dev Neurobiol 71:45-61. CrossRef Medline

Shepherd GM, Svoboda K (2005) Laminar and columnar organization of ascending excitatory projections to layer $2 / 3$ pyramidal neurons in rat barrel cortex. J Neurosci 25:5670-5679. CrossRef Medline

Shepherd GM, Pologruto TA, Svoboda K (2003) Circuit analysis of experience-dependent plasticity in the developing rat barrel cortex. Neuron 38:277-289. Medline

Silberberg G, Markram H (2007) Disynaptic inhibition between neocortical pyramidal cells mediated by Martinotti cells. Neuron 53: 735-746. CrossRef Medline

Somogyi P (1977) A specific "axo-axonal" interneuron in the visual cortex of the rat. Brain Res 136:345-350. Medline

Sotelo C (2003) Viewing the brain through the master hand of Ramón y Cajal. Nat Rev Neurosci 4:71-77. CrossRef Medline

Thomson AM, Bannister AP (1998) Postsynaptic pyramidal target selection by descending layer III pyramidal axons: dual intracellular recordings and biocytin filling in slices of rat neocortex. Neuroscience 84:669-683. Medline

van Pelt J, van Ooyen A (2013) Estimating neuronal connectivity from axonal and dendritic density fields. Front Comput Neurosci 7:160 CrossRef Medline

Yizhar O, Fenno LE, Prigge M, Schneider F, Davidson TJ, O'Shea DJ, Sohal VS, Goshen I, Finkelstein J, Paz JT, Stehfest K, Fudim R, Ramakrishnan C, Huguenard JR, Hegemann P, Deisseroth $\mathrm{K}$ (2011) Neocortical excitation/inhibition balance in information processing and social dysfunction. Nature 477:171-178. CrossRef Medline

Yuste R (2005) Origin and classification of neocortical interneurons. Neuron 48:524-527. CrossRef Medline

Zhang W, Huguenard JR, Buckmaster PS (2012) Increased excitatory synaptic input to granule cells from hilar and CA3 regions in a rat model of temporal lobe epilepsy. J Neurosci 32:1183-1196. CrossRef Medline

Zhou FW, Roper SN (2010) Densities of glutamatergic and GABAergic presynaptic terminals are altered in experimental cortical dysplasia. Epilepsia 51:1468-1476. CrossRef Medline 